
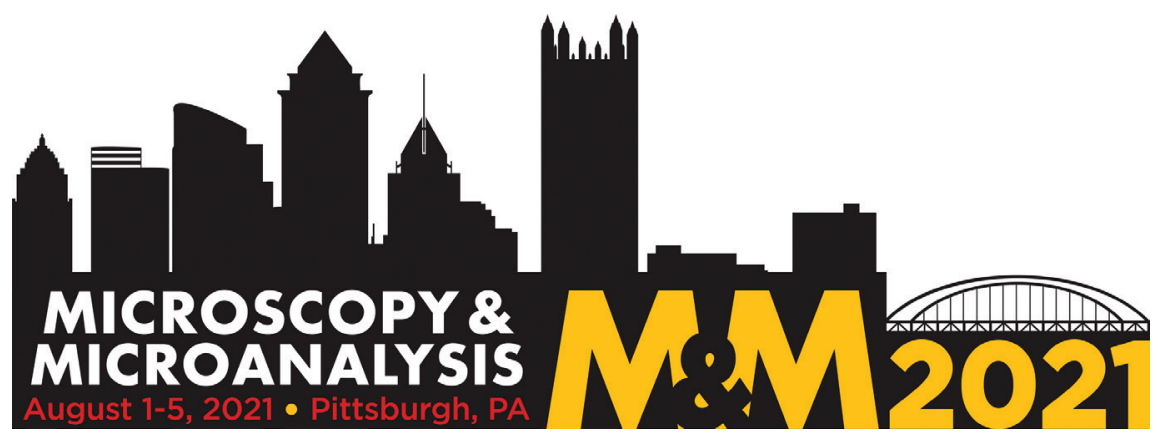

\title{
Meeting Preview
}

\section{Microscopy and Microanalysis 2021 in Pittsburgh, PA}

\author{
Elizabeth Wright, Program Chair \\ University of Wisconsin, Madison, WI 53706 \\ erwright2@wisc.edu
}

The Microscopy Society of America (MSA) and the Microanalysis Society (MAS) invite you to attend Microscopy \& Microanalysis 2021 (M\&M 2021) in Pittsburgh, PA, August 1 through August 5, 2021. This is the third time that M\&M will be held in Pittsburgh; our last meeting in the "Steel City" was in 1961! Pittsburgh is located in Western Pennsylvania, where the Allegheny, Monongahela, and Ohio Rivers meet. It has been a central hub between the East Coast and Midwest, for the industrial revolution, and for health and technology corporations. With its numerous waterways and distinctive topography, Pittsburgh or the "City of Bridges" remains connected through its 446 unique bridges. Pittsburgh is rich with skyscrapers, industrial design, educational and research institutions, museums, the cultural district, sports attractions, and natural wonders. There will be a lot to explore in and around Pittsburgh, and with temperatures in the $80 \mathrm{~s}^{\circ} \mathrm{F}\left(\sim 27^{\circ} \mathrm{C}\right)$, it is sure to be comfortable t-shirt and shorts weather.

We are excited to welcome you to another great M\&M meeting! We are hopeful that M\&M 2021 will be an on-site and face-to-face meeting after we held M\&M 2020 as a virtual meeting. However, regardless of an on-site or virtual meeting, the scientific content of M\&M 2021 will feature outstanding plenary speakers, symposia, pre-meeting and in-meeting educational opportunities, and, of course, a range of social events to enhance the meeting experience.

The meeting will begin with the now traditional MSA Student Council's Annual Pre-Meeting Congress highlighting outstanding work by student and postdoctoral fellow attendees. There will also be two other Pre-Meeting Congresses: "Contemporary Electron Microscopy Advances in Biomedical Research" sponsored by the MSA Diagnostic and Biomedical Microscopy Focused Interest Group (FIG) and "Recent Developments in Advanced Imaging and Spectroscopy" organized by the MSA Aberration-Corrected Electron Microscopy FIG. These pre-meeting events will be complemented by six Sunday Short Courses that will cover various topics, including CryoEM, Biological Fluorescence Microscopy, 4D-STEM, Serial
EM, Operando Approaches to TEM, and Data Analysis in Materials Science.

The meeting itself will feature six plenary speakers, 36 symposia covering a broad range of topics, and numerous educational opportunities through courses and tutorials. And, as we have come to expect, M\&M 2021 will have the largest instrument and vendor exhibition in the world. Attendees will have the opportunity to see the latest equipment and services from over 130 companies. The latest developments in microscopy instrumentation and techniques and applications in biological and physical sciences will be presented during the technical sessions and exhibits.

Our first slate of plenary speakers will include Dr. Kizzmekia Corbett, a senior research scientist in the Vaccine Research Center at the NIH, and Dr. Jason McLellan, a Professor in the College of Natural Sciences at the University of Texas, Austin. They are both coronavirus experts. Dr. Corbett and Dr. McLellan are at the pandemic front lines with cryo-EM

\section{Biological Science Plenary Speakers}

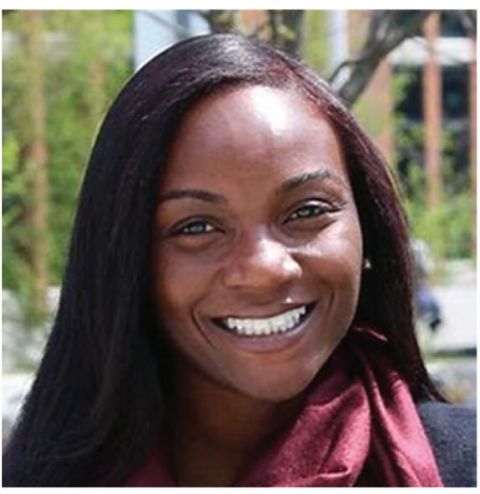

Kizzmekia S. Corbett National Institutes of Health Vaccine Research Center

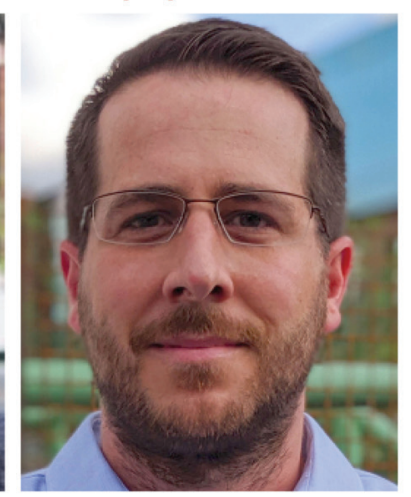

Jason McLellan

University of Texas at Austin College of Natural Sciences 


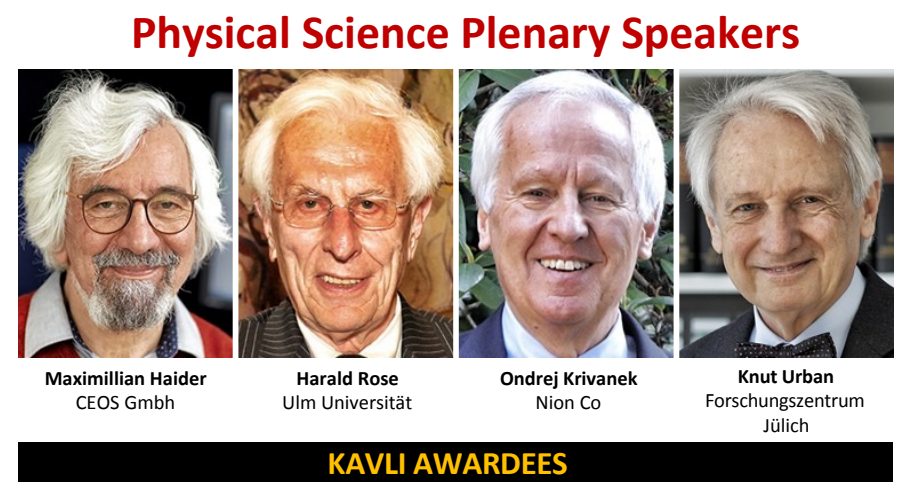

structural and functional studies of SARS-CoV-2 and the development of COVID-19 vaccine candidates.

Our second group of plenary speakers will include Dr. Maximillian Haider, co-founder of CEOS GmbH; Dr. Ondrej Krivanek, co-founder and president of Nion Co.; Dr. Harald Rose, Professor Emeritus of Physics at Ulm Universität and the University of Darmstadt; and Dr. Knut Urban, the former Director of the Institute of Microstructure Research at Forschungszentrum Julich. They are all pioneers in the field of aberration correction in electron microscopy. Dr. Haider, Dr. Krivanek, Dr. Rose, and Dr. Urban won the 2020 Kavli Prize in Nanoscience for sub-Ångstrom resolution imaging and chemical analysis using electron beams. Visit the M\&M 2021 website to learn more about our M\&M 2021 Plenary speakers!

The Program Committee, together with the symposium organizers, has developed an exciting collection of 36 symposia that spans topics including advances in instrumentation and technique development and applications in the analytical, biological, and physical sciences. We encourage you to browse through the Call for Papers for the complete list of symposia and submit one or more contributions for platform or poster presentations.

Complementing the Pre-meeting Congresses and 36 symposia will be five In-Week Tutorials, and three Technologists' Forum sponsored events. The In-Week Tutorials will be: "Cryo-EM Structure Determination of Small Proteins," "Traversing Spatial Scales with Correlative Microscopy," "Entrepreneurship in the Microscopy Community," "Monochromated Aberration Corrected STEM: Why?" and "X-Ray Imaging \& Computed Tomography.” Technologists' Forum topics include roundtable discussions on "Technical Careers in Microscopy Ph.D. Not Required" and "Histology Helpline" and a workshop on "Technique/Tips: Special Stains and Serial Sectioning."

Last but not least, there will be a full complement of Microscopy Outreach sessions in Pittsburgh: ProjectMICRO, our popular microscopy outreach workshop, will be in the MegaBooth all week. See different microscope systems and learning stations for use in the classroom, peruse books suitable for elementary school-age children, and share your experiences of how you have fun with microscopy. Microscopy in the Classroom will continue with its "STEM Roundtable" session. Come join the conversation with educators, industry leaders, and other key stakeholders who are invested in STEM education! Microscopy in the Classroom provides a unique educational experience for high school and undergraduate students outside the traditional classroom. Microscopy Explorations for Families and Kids of All Ages (formerly Family Affair) returns for another year of on-site microscopy games, exploration, and fun!

A large number of social activities await you in Pittsburgh, including the opening reception, intermission at the Plenary session, refreshments during the daily poster sessions, student and postdoctoral scholar mixers, and many vendor-sponsored events. Prize-winning student posters will be announced each day, in addition to an award for the best poster utilizing ultramicrotomy, the Microscopy Today Innovation and Micrograph contests, and the very popular Passport to Prizes with some outstanding gifts sponsored by our exhibitors. We are happy to announce that M\&M 2021 will once again offer Childcare Service for children between the ages of 6 months and 12 years to support parents with young children so they can attend the many meeting events.

For a complete description of the M\&M 2021 technical program and educational opportunities, please go to Welcome | M\&M 2021 Microscopy \& Microanalysis. Details for the Call for Papers and other aspects of the program and meeting are provided under the "Scientific Program" button.

Whether on-site or virtual, the Executive Program Committee welcomes you to attend M\&M 2021 for an extraordinary and compelling event. Join us to catch up with old friends and make new ones! On behalf of MSA and MAS, in cooperation with over one hundred symposium organizers and countless volunteers, we look forward to seeing you at M\&M 2021 this August!

\section{MT}

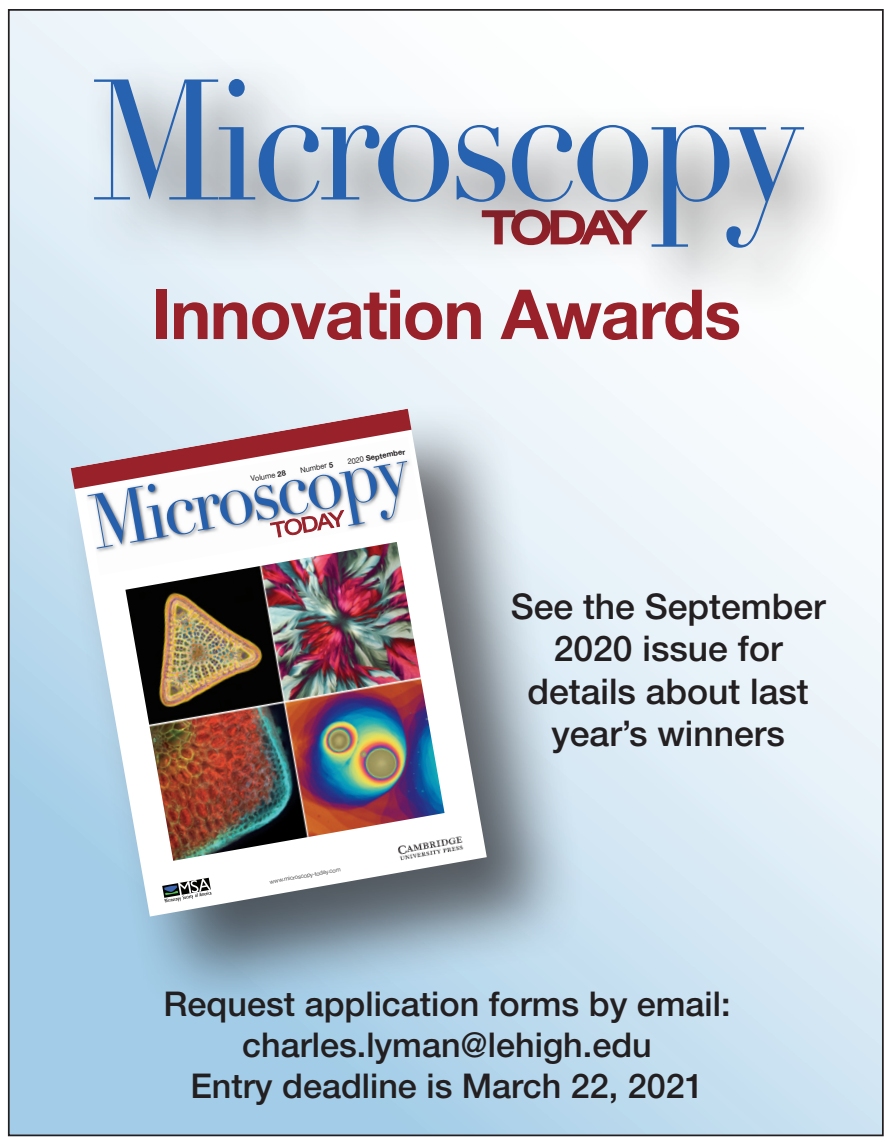

